http://jmscr.igmpublication.org/home/

ISSN (e)-2347-176x ISSN (p) 2455-0450

crossref DOI: https://dx.doi.org/10.18535/jmscr/v7i7.166

Journal Of Medical Science And Clinical Research

\title{
Impacted Mid Ureteric Stone: Comparative Study of Treatment by Transperitoneal Laparoscopic Ureterolithotomy versus Ureteroscopy
}

\author{
Authors \\ R K Maurya ${ }^{1}$, Prabu R ${ }^{2}$, Vinay Kumar ${ }^{3}$, K B Mishra ${ }^{4}$ \\ ${ }^{1,4}$ Professor, Department of Surgery, GSVM Medical College, Kanpur \\ ${ }^{2}$ Senior Resident, Department of Surgery, GSVM Medical College, Kanpur \\ ${ }^{3}$ Assistant Professor, Department of Surgery, GSVM Medical College, Kanpur
}

\begin{abstract}
Objective: To compare the effectiveness and complications of ureteroscopy (URS) with pneumatic lithotripsy and transperitoneal laparoscopic ureterolithotomy (TPLU) in treatment of impacted mid ureteric stones larger than $1 \mathrm{~cm}$.

Materials and Methods: In this prospective randomised study, 60 patients with impacted mid ureteric stone underwent URS with either pneumatic lithotripsy (group 1) or TPLU (group 2). Patient's demographic profile, success rate, re-treatment rates, operation time, hospital stay, auxiliary procedures and complications were compared between group A and group $B$.

Results: Sixty patients (URS group 30, TPLU group 30) met inclusion criteria. It was seen that both methods were effective in the treatment of large mid ureteric stone; however, TPLU provide higher stone clearance rate (100 vs. $86.67 \%)$, lower complication rate and shorter operation time (61.66 $\pm 8.34 \mathrm{vs} .85 .67$ $\pm 7.62 \mathrm{~min}$ ). On the other hand, patients treated with pneumatic ureteroscopy had less postoperative pain, shorter hospital stay and faster return to daily activities.

Conclusions: For treatment of impacted large mid ureteric stone, TPLU provides significantly higher success rate and lower retreatment rate compared with pneumatic ureteroscopy; however, URS provides similar stone free rates at three months as a minimal invasive procedure.

Keywords: Mid ureteric stones, pneumatic ureteroscopy, transperitoneal laparoscopic ureterolithotomy.
\end{abstract}

\section{Introduction}

Ureteral calculus is more symptomatic and prone to deterioration of renal function when compared to renal stones. Indications for active treatment of ureteral stones include large calculi with low spontaneous passage, persistent pain, obstruction, or renal failure. Extracorporeal shock-wave lithotripsy (SWL) and uretero-renoscopy (URS) are the first choices for active treatment of ureteral calculi. Necessity of open or laparoscopic procedures is limited with the evolution of modern lithotripsy and ureteroscopy. URS has been found to be more effective than SWL for ureteral calculi that are bigger than $10 \mathrm{~mm}$ in diameter with success rates of more than $80 \%$. URS success rates are decreased in mid-or-upper-ureter stones. Currently, laparoscopic ureterolithotomy is indicated for large impacted stones when other minimal invasive procedures fail.

Large impacted mid ureteral calculus is defined as a stone of more than $10 \mathrm{~mm}$ size located between fifth lumbar vertebra to lower border of sacro-iliac 
joint, remaining in the same position for at least 2 months with or without failure of visualization of ureter distal to mid ureter stone in intravenous urography (IVU) / CT urogram confirming the presence of the stone in same position since two months. Failure of retrograde passage of a guide wire beyond the stone is sometimes present with impaction; however, this may be due to the transient lie, mucosal oedema and irregular surface of the stone making a niche in the ureteric wall.

The optimal management of impacted mid ureteric stone is still controversial with no established guidelines for the treatment of choice. Considering this we undertook a comparative trial of URS with pneumatic lithotripsy versus transperitoneal laparoscopic ureterolithotomy (TPLU).

\section{Materials and Methods}

We conducted this prospective randomised comparative study over a period of 24 months (Jan 2016 to Jan 2018) on patients admitted in Department of General surgery, LLR and associated hospital, Kanpur and Kanpur urology centre, Kanpur. Inclusion criteria comprised patients with solitary, mid ureteric stone, stone size of $10 \mathrm{~mm}$ and above, located between fifth lumbar vertebra to lower border of sacro-iliac joint, and diagnosed by excretory urography or CT. Stone size was measured using ultrasound KUB or CT. Apart from clinical history and examination,complete blood count, renal function test, liver function test, serum calcium, serum uric acid, urine culture and sensitivity, renal and bladder ultrasound, coagulation profile, and kidney, ureter, bladder X-ray or CT were performed. Informed written consent was obtained before randomization and surgical intervention. The randomization was done on a 1:1 basis. Group 1 consisted of patients who underwent URS with pneumatic lithotripsy and group 2 consisted of those treated with TPLU.

\section{Operative Techniques}

\section{URS Procedure}

The patient in group 1 underwent URS with 6/7.5 URS. Wherein the guide wire was placed on ipsilateral side and all attempts were made to bypass the stone. A 10mgfrusemide was given intravenous before putting the guide wire. In difficult situation of failure to bypass its tip was placed at distal end of the stone under fluoroscopic control (flagging of stone). The pneumatic lithotripter was used to fragment the stone and all stones were retrieved with the aid of forceps. A DJ stent was placed in the end along with a 16 F Foley catheter.

\section{Transperitoneal laparoscopic ureterolithotomy}

The patients in group 2 were placed in supine position and three standard ports were made. One camera port $(10 \mathrm{~mm})$ atthe umbilicus, one $10 \mathrm{~mm}$ port in mid clavicular line at level of umbilicus and one $5 \mathrm{~mm}$ port at supra pubic region. $\mathrm{CO} 2$ pneumoperitoneum was maintained at $12 \mathrm{~mm} \mathrm{Hg}$. The port site could be varied depending upon the obesity of patients. The head end was lowered down and bowels were reflected upwards and the ureter was identified by bulge of the stone and peristalsis. The peritoneum over it was reflected and the stone was locked by bowel grasper (clamping the ureter proximally). A hook was used to cut the ureter and the stone was delivered in. A double $\mathrm{J}$ stent was placed from above using the hollow suction probe. The ureter was stitched by interrupted 3-0 vicryl suture. A tube drain was put in the lower abdomen after covering with overlying peritoneum. The stone was taken out by the $10 \mathrm{~mm}$ port using $5 \mathrm{~mm}$ telescope. The postoperative drugs, analgesia and recovery, including immediate and late complications were also charted and recorded for up to three months of the procedure. The DJ stent placed preoperatively was removed after 15 days. The post op IVU/CT urogram was done after 3 months of procedure to ascertain the renal functional recovery \& to rule out ureteric stricture/ residual stones. 


\section{JMSCR Vol||07||Issue||07||Page 943-948||July}

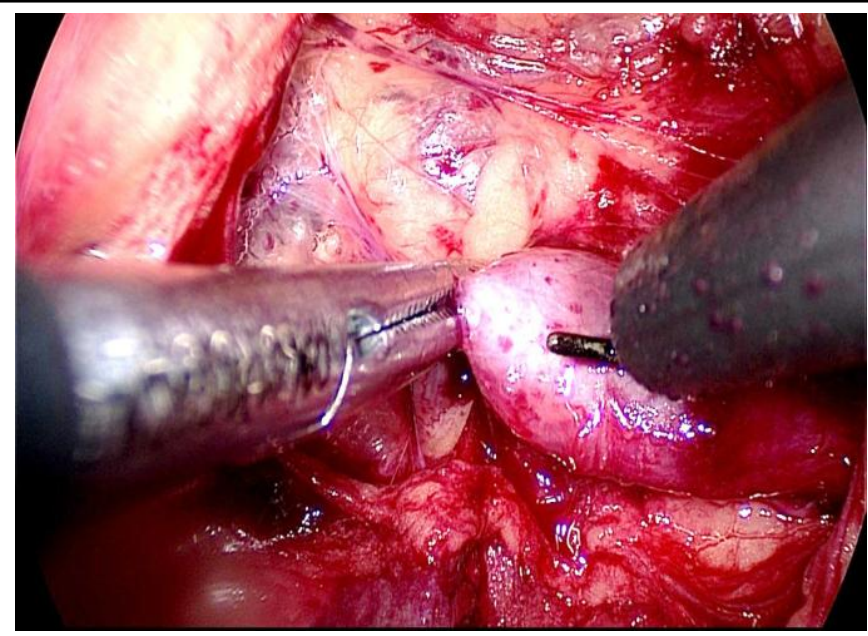

Figure 1- shows stony bulge and incision for ureterotomy

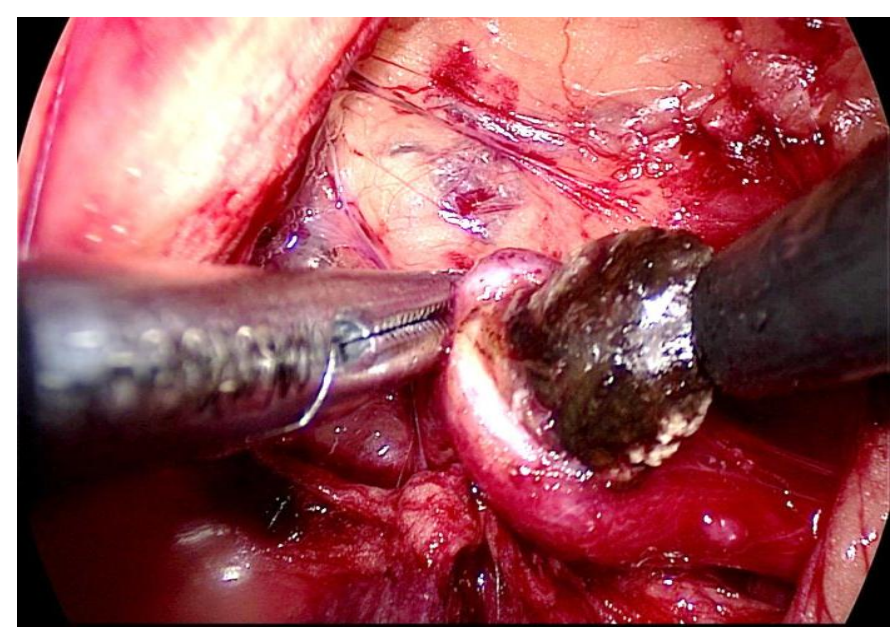

Figure 2- shows delivery of stone from ureter

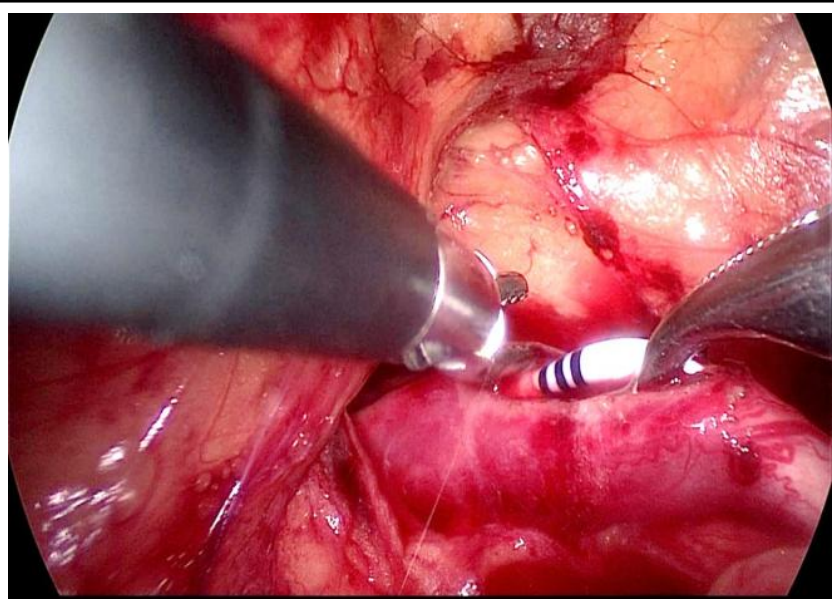

Figure 3-DJ stenting after removal of ureteric stone

\section{Statistical analysis}

Statistical analysis was performed using SPSS version 16.0, using unpaired ' $t$ ' test and ' $z$ ' test for testing the proportion and difference between the two groups. Statistical significance was considered at $\mathrm{p}<0.05$.

\section{Results}

The demographic characteristics of the 2 groups are shown in table 1. There was no significant difference between the 2 groups with respect to gender, serum creatinine, serum uric acid levels, side of involvement, stone size.

Table 1 Patient demographics, perioperative data

\begin{tabular}{|l|c|c|c|c|}
\hline & Group 1 & Group 2 & $\mathrm{t}$ & $\mathrm{p}$ value \\
\hline No. of patients & 30 & 30 & - & - \\
\hline Mean \pm SD patient age & $40 \pm 12$ & $46.77 \pm 7.05$ & 2.66 & 0.009 \\
\hline No of male/ female & $22: 8$ & $19: 11$ & - & - \\
\hline Mean \pm SD serum creatinine & $1.07 \pm 0.21$ & $1.07 \pm 0.17$ & - & - \\
\hline Mean \pm SD uric acid & $5.30 \pm 1.77$ & $5.86 \pm 1.44$ & 1.34 & 0.1841 \\
\hline No of Rt $:$ Lt side of involvement & $13: 17$ & $16: 14$ & - & - \\
\hline Mean \pm SD stone size (mm) & $15.18 \pm 1.59$ & $14.60 \pm 2.02$ & 1.23 & 0.2215 \\
\hline Mean \pm SD operative time (min) & $85.67 \pm 7.62$ & $61.66 \pm 8.34$ & 11.64 & 0.0001 \\
\hline $\begin{array}{l}\text { Stone clearance rate (plain x- ray + } \\
\text { ultrasound KUB ) }\end{array}$ & $86.67 \%$ & $100 \%$ & - & - \\
\hline Mean \pm SD hospital stay (days) & $3.1 \pm 1.02$ & $4.6 \pm 0.81$ & 6.30 & 0.0001 \\
\hline$\%$ auxiliary procedure & $16.67 \%$ & 0 & - & - \\
\hline
\end{tabular}

Table 2. Comparison of postoperative complications

\begin{tabular}{|l|c|c|c|}
\hline & Group 1 & Group 2 & $\mathrm{p}$ value \\
\hline $\begin{array}{l}\text { No of paralytic ileus (absent bowel sound } \\
\text { more than 36 hrs) }\end{array}$ & $2 / 30(6.67 \%)$ & $4 / 30(13.33 \%)$ & $0.86(\mathrm{z}$ test $)$ \\
\hline No haematuria & $3 / 30(10 \%)$ & $2 / 30(6.67 \%)$ & $0.57(\mathrm{z}$ test $)$ \\
\hline No febrile urinary tract infection & $3 / 30(10 \%)$ & $2 / 30(6.67 \%)$ & $0.57(\mathrm{z}$ test $)$ \\
\hline No of ureteral perforation & $2 / 30(6.67 \%)$ & 0 & - \\
\hline
\end{tabular}


For URS, patients were placed in lithotomy position after receiving spinal $(85 \%)$ or general anaesthesia $(15 \%)$. Mean duration of procedure ranged from 55 to 130 minutes (mean $85.67 \pm$ 7.62) and mean radiation exposure was $3.2 \pm 1.8$ minutes. A semi rigid ureteroscope was passed into ureter using safety wire and stone visualization was possible in $88 \%$ of procedures. Fragmentation was performed through pneumatic lithotripsy. Intra-operative push up of stone fragments was noted in $36 \%$ of procedures. A double $\mathrm{J}$ ureteral catheter was placed in $92 \%$ cases, and second look ureteral procedure was necessary in $28.5 \%$. In 2patients ureteral perforation was occurred, and were managed conservatively. Urinary tract infection developed in 3 patients (reverted). No major complication occurred.

Laparoscopic ureterolithotomy was performed through a transperitoneal route with the patient under general anaesthesia. Ureterotomy size varied from 1 to $3 \mathrm{~cm}$. Difficulties during surgical procedures included an intense peri-ureteral inflammation, stone migration and difficult ureteral catheter placement. A double J stent was placed. Neither urinary leaks nor major complications occurred.

Overall stone clearance rate after 1 and 4 weeks of treatment was (100 \% $\quad$ vs. $86.67 \%)$ significantly higher for TPLU than URS with pneumatic lithotripsy. The auxiliary procedure rate $(16.67 \%)$ was significantly higher for URS than TPLU. The mean duration of hospital stay between 2 groups were statistically significant. The most common postoperative complication was paralytic ileus (absent bowel sound for more than 36 hours) seen in 4 patients in group 2 (statistically not significant).

\section{Discussion}

Urinary stone treatment has evolved in recent decades and minimally invasive procedures can be performed for urinary calculi in almost all situations. However, large, impacted mid ureteric stones are still a point of controversy. The success of procedures in treating these calculi varies according to different series, but in majority of centres ureterolithotomy (open or laparoscopic) seems to be mostly indicated after failure of SWL or URS. In this context laparoscopic ureterolithotomy seems to be more advantageous than open procedure.

When defining the best procedure to treat these calculi, it should be not only minimally invasive but highly effective. There is no doubt that URS is less invasive and laparoscopic ureterolithotomy is most invasive procedure. However, although URS is less invasive, it has some limitations for these impacted stones. Ureteroscopic procedures are mostly limited by an inability to reach the stone, especially in men, and also by frequent ureteral lesions (oedema, polyps, and strictures) associated with impacted stones. It has been postulated that long term impaction is the most important predictor of failure in these cases.

Our study has some important findings. URS is a minimally invasive procedure and is associated with acceptable success rate (86.67\%). Laparoscopic ureterolithotomy has significantly higher morbidity than URS, requires long hospital stay $(4.6 \pm 0.81$ vs3 $3 \pm 1.02$ days, $\mathrm{p}<0.0001)$, causes more post treatment pain and requires more opioids to treat the pain. However success rate of TPLU is more satisfactory than that of URS (100 $\%$ vs $86.67 \%$ ).

\section{Conclusion}

Large impacted mid ureteric stone treatment requires multiple procedures until complete stone free status is achieved. TPLU is associated with higher success rate, and a lower number of surgical procedures, but with more postoperative pain, and a longer stay than URS; however, URS provides similar stone free rates at three months as a minimal invasive procedure.

\section{Declarations}

Funding: None

Conflicts of interest: None declared. 
Ethical approval: The work has been approved by the Institutional Ethics Committee, GSVM Medical College, Kanpur, UP, India.

\section{References}

1. Erhard M, Salwen J, Bagley DH. Ureteroscopic removal of mid and proximal ureteral calculi. $\mathrm{J}$ Urol1996;155:38-42

2. Khaladkar S, Modi J, Bhansali M, Dobhada S, Patankar S : Which is the best option to treat large $(>1.5 \mathrm{~cm})$ midureteric calculi? J Laparoendosc Adv Surg Tech A. 2009 Aug;19(4):501-4.

3. Preminger GM, Tiselius HG, Assimos DG, Alken P, Buck C, Gallucci M, et al. 2007 guideline for the management of ureteral calculi. J Urol. 2007; 178:2418-34.

4. Hendrikx AJ, Strijbos WE, de Knijff DW, Kums JJ, Doesburg WH, LemmensWA : Treatment for extended-mid and distal ureteral stones: SWL or ureteroscopy? J Endourol. 1999 Dec; 13(10): 727-33.

5. Goel A, Hemal AK. Upper and midureteric stones: a prospective unrandomized comparison of retroperitoneoscopic and open ureterolithotomy. BJU Int 2001;88: 679-82.

6. Segura JW, Preminger GM, Assimos DG, et al. Ureteral Stones Clinical Guidelines Panel summary report on the management of ureteral calculi. The American Urological Association. J Urol1997;158: 1915-21.

7. Kaygısız O, Coşkun B, Kılıçarslan H, et al. Comparison of ureteroscopic laser lithotripsy with laparoscopic ureterolithotomy for large proximal and mid-ureter stones. Urol Int. 2015;94(2):205-9. doi: 10.1159/000368374. Epub 2015 Jan 29

8. Prakash J1, Singh V, Kumar M, Kumar M, Sinha RJ, Sankhwar S.et al , Retroperitoneoscopic versus open miniincision ureterolithotomy for upper- and mid-ureteric stones: a prospective randomized study. Urolithiasis. 2014Apr; 42(2):133-9. doi: 10.1007/s00240-0130624-1. Epub 2013 Nov 23.

9. Keeley FX, Gialas M, Pillai M, Chrisofos M, Tolley DA. Laparoscopic ureterolithotomy: the Edinburgh experience. BJU Int 1999; 84: 765 \pm 9

10. Harewood LM, Webb DR, Pope AJ. Laparoscopic ureterolithotomy: the results of an initial series, and an evaluation of its role in the management of ureteric calculi. Br J Urol 1994; 74: 170 \pm 6

11. Roberts WW, Cadeddu JA, Micali S, Kavoussi LR, Moore RG. Ureteral stricture formation after removal of impacted calculi. J Urol 1998; 159: 723 \pm 6

12. Gaur DD, Agarwal DK, Darshane AS, Purohit KC. Laparoscopic ureterolithotomy: our experience with 17 patients. Bombay Hospital J 1993; 35: 65 \pm 8

13. Tunc L, Kupeli B, Senocak C, Alkibay T, Sözen S, Karaoglan U, et al. Pneumatic lithotripsy for large ureteral stones: Is it the first line treatment? Int Urol Nephrol.2007;39:759-64.

14. Coptcoat MJ, Coker C, Mulvin DM. Laparoscopy in urology: a clinical review of 359 cases. In Hemal AK ed. Laparoscopic Urologic Surgery: Retroperitoneal and Transperitoneal. Chapt 37. New Delhi: BI Churchill Livingstone, 2000: 309 \pm 22

15. Blute ML, Segura JW, Patterson DE. Ureteroscopy. J Urol 1988; 139: 510 \pm 2

16. Park H, Park M, Park T. Two year experience with ureteral stones: extracorporeal shockwave lithotripsy vs ureteroscopic manipulation. J Endourol 1998; 12: 501 \pm 4

17. Wickham JEA. The surgical treatment of urinary lithiasis. In Wickham JEA ed. Urinary Calculus Disease. Edinburgh: Churchill Livingstone, 1979: 145 \pm 98

18. Bellman GC, Smith AD. Special considerations in the technique of 
laparoscopic ureterolithotomy. J Urol 1994;151: $146 \pm 9$

19. Gaur DD, Agarwal DK, Purohit KC, Darshane AS, Shah BC. Retroperitoneal laparoscopic ureterolithotomy for multiple upper mid ureteral calculi. J Urol 1994; 151:1001 \pm 2

20. Turk I, Deger S, Roigas J, Fahlenkamp D, Schonberger B, Loening SA. Laparoscopic ureterolithotomy. Tech Urol 1998; 4: 29 \pm 3

21. Perez Castro E1, Osther PJ2, Jinga V3, Razvi H4, Stravodimos KG5, Parikh K6, Kural AR7, de la Rosette JJ8; CROES Ureteroscopy Global Study Group. Differences in ureteroscopic stone treatment and outcomes for distal, mid, proximal, or multiple ureteral locations: the Clinical Research Office of the Endourological Society ureteroscopy global study Eur Urol 2014Jul;66(1):1029.

22. Singh V1, Sinha RJ, Gupta DK, Kumar M, Akhtar A. Transperitoneal versus retroperitoneal laparoscopic ureterolithotomy: a prospective randomized comparison study. J Urol. 2013 Mar;189(3):940-5.

23. Bader MJ, Eisner B, Porpiglia F, Preminger GM, Tiselius H (2012) Contemporary management of ureteral stones. Eur Urol 61:764-772

24. Degirmenci T, Gunlusoy B, Kozacioglu Z, Arslan M, Kara C, Koras O, Minareci S (2012) Outcomes of ureteroscopy for the management of impacted ureteral calculi with different localizations. Urology 80:811-815

25. Preminger GM, Tiselius HG, Assimos DG, Alken P, Buck C, Gallucci M et al (2007) 2007 Guideline for the management of ureteral calculi. J Urol 178:2418
26. Schuster, T.G., Hollenbeck, B.K., Faerber, G.J., Wolf, J.S. Jr. Complications of ureteroscopy: analysis of predictive factors. J Urol. 2001;166:538-540.

27. Bierkens, A.F., Hendrikx, A.J., De La Rosette, J.J. et al, Treatment of mid- and lower ureteric calculi: extracorporeal shock-wave lithotripsy vs laser ureteroscopy. A comparison of costs, morbidity and effectiveness. $\mathrm{Br} \mathrm{J}$ Urol. 1998;81:31-35. 